\title{
Feasibility Analysis of Seawater Desalination in Urban Municipal Water Supply in Coastal Cities
}

\author{
Boyu Liu 1, a, Chengpu Liu ${ }^{2, b}$, Rongwang Guo ${ }^{3, c}$, Jinfeng Jiao ${ }^{4, d}$ \\ 1,2,3,4 Jiangsu Province Xuzhou City Yunlong District Tongshan Road,College of Engineer Corps \\ aliupeng412144113@126.com, b412144113@qq.com, crongwangg@163.com, djjfeng@163.com
}

Keywords: Seawater desalination Municipal water supply Feasibility analysis

\begin{abstract}
China cities are in the state of shortage of water in recent years. Although large scale projects have solved some of the city's municipal water supply problems, the linear water supply policy still can't cover all the small and medium-sized city. In recent years, seawater desalination technology has becom mature. In this paper the feasibility of the city's municipal water supply in some cities is analyzed in-depth.
\end{abstract}

\section{Introduction}

At present, large scale projects such as the implementation of the South to North Water Diversion Project has solved some of the city's municipal water supply problems, the linear water supply policy still can't cover all the small and medium-sized city. Especially in the eastern coastal cities, the water supply problem has not gotten better external supply. In recent years, some Coastal cities begin to be incorporated into the strategic water sources, and begin to research and demonstrate. The feasibility of cities desalination and desalination of sea water, whether it can become a new source of economic and social development in the coastal areas of China, becomes a problem that needs to be demonstrated.

\section{The present situation and solutions of city municipal water resources}

Some cities have been serious water shortage, they solve the problem by water diversion from the surrounding area all the time. From a modern point of view, long distance water transferring is neither economical nor environmentally friendly. Sea water desalination is the only way to solve the problem of water shortage in coastal cities. Sea water desalination has opened up a new source of water, and coastal cities are belong to the near distance for water transferring. It not only can solve the water shortage as pressing danger, but also does not plunder the precious water resources water arounding water-deficient areas. At the technical level, China already has the technical level of sea water desalination.

Raising the price of water, water conservation, relocation of high water consumption enterprises are the basic measures to solve the problem of water resources in the city. These measures are effective, but they are not the fundamental way. At present, first, for the price of water, the city has no yet sound and perfect price system of water resources. The price of water also fails to play its leverage. Tap water, surface water, underground water, sewage, water price ratio is not conducive to the rational allocation of water resources. Raising the price of water and international situation step by step also need to take into account the national conditions, and economic capacity of the masses of the people, which should be cautious. Second, for the conservation of water, water conservation is a social norm and morality that the whole people must obey. According to the current level of science and technology, various industries develop a reasonable water quota, implement total amount control, reduce waste, manage the "faucet". They should be good and should always be a way to stick to it. But this approach is limited to the mitigation of water resources. Third, for the relocation of water consuming enterprises, this is a good measure, but it will inevitably bring to the problem of laid-off workers and tax losses. At present, the city's industrial structure is not reasonable, and is not suitable 
for urban water resource conditions. High water consumption of the industry still occupies a considerable proportion. Such as metallurgy, petrochemical, textile and other traditional industries occupy a considerable proportion, the future direction of development should make modern manufacturing industry of low water consumption and high added value to transform the traditional industry.

\section{Cost analysis of municipal water supply in the implementation of sea water desalination}

At present, most of the city's water resources have no much room for open source, It can only be made choice in two aspects of water transferring and sea water desalination. Firstly, in comparison of the cost of water transferring project and seawater desalination, water diversion project length has more than $1000 \mathrm{~km}$, the cost will be much greater than the sea water desalination, the cost of water diversion project in the fifty or sixty's is less than the cost of desalination. However, with the increasing of water transferring distance and price factors, there is also a substantial increasing in the cost of relocation. Secondly, water transferring did not increase the total amount of water resources. It is just the distribution of the limited water in the area between the shunt. Spanish scientists have calculated that when the water transferring is more than $1000 \mathrm{~km}$ to the terminal, the cost is four times as much as that of the sea water desalination. In Spain, the cost of desalination is about 45 euro per cubic meter ( about 4.81 yuan) .If it's used in municipal water supply, the cost can be recovered completely. This price is acceptable in some developed coastal cities. So, the key to the problem is the change of ideas. It should be realized by the land and water resources balance management to the development of new water sources and water reuse management changes. If it depends entirely on water diversion project to solve water problems, then no matter from the economic point of view, environmental protection or social perspective, it will be subject to certain constraints. And if using new technologies and new means to develop new sources of water to ease the contradiction between supply and demand of water resources, this is bound to become an inevitable.

The international practice to solve the problem of urban water supply is to use seawater desalination and waste water reusing. In the Middle East, for example, the country is basically relying on sea water desalination to solve the problem. The total length of China's coastline is thirty-two thousand $\mathrm{km}$, marine resources are very rich and the sea is inexhaustible. The eastern coastal cities are close to the sea, so it can be considered to solve the problem of urban water resources by sea water desalination. Seawater desalination technology is becoming more and more mature, which has become the world's many countries and cities' basic source of water for survival.

Sea water desalination is production of fresh water by desalination of sea water, which is the best means to achieve the open source of water increment. And this is not affected by time and space and climate, water quality is good, the price is reasonable, but also can protect the coastal and offshore residents' living water and industrial water and so on. In recent years, the Chinese government vigorously promote the industry of sea water desalination. In 2005, the national development and Reform Commission and other three ministries introduced "Seawater utilization project" , it plans that the total amount of sea water desalination amounts to 1 billion tons per year until 2020.Tianjin port new spring, China's largest sea water desalination plant, whose sea water desalination project has the production of 100 thousand tons per day in the first phase of construction. It have been completed in July of the year 2009, and will eventually form a capacity of 200 thousand tons per day. Tianjin is one of China's early implementation of the desalination of sea water, its desalination technology is in the domestic leading level. Back in the 80's of the last century, Tianjin has built China's first desalination industrial production equipment. At present, Tianjin's annual desalination capacity reaches one hundred million tons.

For a long time, running water, water diversion projects and other water conservancy facilities are built by the national investment. The price of water uses the government pricing, but doesn't reflect its market value, resulting in the low price of water. However, the sea water desalination is based on market-oriented operation, which should take into account the cost of investment and operating costs. This unequal cost calculation results in a greater difference in cost. On the desalination industry, because the current city water price level and the cost of sea water desalination has the big disparity, 
so this requires the desalination technology research and development and equipment development enterprises to make full use of the national incentive policies, and strive to reduce the cost of desalination equipment, improve the quality of technical services. The local government of the place where the sea water desalination project should actively promote the connection of the municipal water supply network and the water supply network of the sea water desalination project, and provide convenience for the water supply of the sea water desalination project. With the progress of science and technology, and the acceleration of the localization of key technological equipment, tons of water investment, tons of water running costs and total costs will continue to decline, the competitive advantage of desalination will be more obvious. At present, the state and some local governments are working to support policy for the desalination of sea water. For example, the construction of water desalination demonstration project is given equal treatment to the construction of water conservancy facilities.And for the water supply enterprises of using sea water desalination,they're given preferential tariff, tax relief, etc. Therefore, The gap between the sea water desalination and water diversion project is gradually narrowing.

The cost of sea water desalination is influenced by many factors, such as the quality of raw water, the choice of desalination technology, infrastructure, the energy used, operation and maintenance, etc. The cost of a specific project should be analyzed according to the specific situation, which is normally calculated by the market way, considering the cost of the investment and operation. Now the price of desalinated water is more and more close to the price of tap water, the popularization of desalinated water is not far away.

The successful experience of Tianjin sea water desalination project, can be well applied to sea water desalination in urban municipal water supply in coastal cities. Firstly, from the point of system equipment, each desalination equipment is independent, increasing in the handing capacity will increase the number of equipment, while a single set of equipment operation mode remains unchanged, so operation, equipment, water stability will not be changed a lot. Secondly, from the point of desalination technology, there are mainly two ways named thermal method and membrane method. Thermal method mainly include multi-stage flash distillation, multi-effect distillation, vapor compression distillation, while membrane method is mainly composed of reverse osmosis, electro-dialysis. These methods all can be used for large-scale desalination project. Reverse osmosis is the main technology used in the desalination project of China, the quantity of output water is 306500 cubic meters per day which accounts for $75 \%$ of the total output water. Followed by the low temperature multiple effect technology, accounting for $23.5 \%$ of the total output water, other methods added up to less than $1.5 \%$. Reverse osmosis desalination technology applied in municipal water supply has a bigger superiority, which is adopted in almost all projects used in municipal water supply. In addition, there are many good project cases from the Middle East countries, Spain, Australia and Singapore according to the experiences to operate it. Australia is the driest continent in the world, since this century, it began to use sea water desalination to solve the increasingly serious water shortage problems. The most typical example, Perth desalination plant put into use in early 2007, was the biggest water desalination project outside the Middle East countries. The quantity of output water is up to 144000 tons per day. This desalination plant uses wind energy which is a type of renewable energy and covers an area of the smallest. Three sea water desalination project including Perth desalination plant account for a third of the total municipal water supply of western Australia. Major cities in Australia like Adelaide, Perth, Melbourne, Sydney, gold coast and Brisbane all will be built large desalination equipment. Spain built the first desalination plants in Europe 40 years ago, which is the largest consumer of desalination technology in the west. Spanish companies take the clean water to homes through the innovation and development of seawater desalination technology. Along the southern coast of the Mediterranean Spain, Europe's biggest water desalination plants is in Carboneras region. Today, in addition to Saudi Arabia, the United Arab Emirates and Kuwait, Spanish is the fourth largest user of seawater desalination technology in the world. Every day more than 700 factories output nearly 1.6 million tons of fresh water in Spain, which ensures the 8 million residents living water. At the end of 2010, Jordan built the first desalination plant in the red sea port 
city Aqaba, which is 300 kilometers from the red sea and supply 10 million cubic meters water to Aqaba a year.

\section{The harmful effects of desalination and handling measures}

In the process of sea water desalination, the plant will discharge condensed water containing high concentration of salt into the ocean. But with the progress of technology, the plant began to consider raising the rate of fresh water recovery, so the quantity of concentrated salt water into the sea is quite trace. The sea water will have a strict pretreatment before desalination, and the phenomenon such as the ocean tides, ocean currents, making condensed water quickly get diluted, so there won't cause pollution. Concentrated brine are directly pouring into the sea in most places around the world. The development zone in Tianjin has designed a circular economy idea using the concentrated brine for salt chemical production, which solved the problem boldly and innovatively. There are also other methods, such as mixing the concentrated water with the processing of municipal sewage water, so both sides of the waste water have been diluted and there won't cause pollution.

\section{Conclusions}

\section{Sea water desalination process will be possible under the unified planning in the government}

The sea water desalination projects which are ongoing or under construction in China are built to meet production needs of enterprises, while there are not projects built purely for municipal engineering. However, the development and reform commission of China and other departments released China's first national planning of desalination during the period of "11th five-year plan", which has played a good role in promoting the development of China's sea water desalination. As for China's current situation, the quantity of the sea water desalination is not more but less. China's current total scale of desalination also couldn't catch up with the size of a large international engineering, and China's coastal towns are the most economically developed and most lack of water and environmental pressure is also the largest area in China. Regional planning of the desalination has been introduced one after another in China's coastal cities and regions which are the main water shortage areas during the "12th five-year plan" period. These projects are exciting, but there are also some problems such as can't meet the city water resources laws and norms after the construction. Furthermore, companies operate without any other and the upside-down relationship between water price and water output made the factory loss or even shut down.

For the healthy development of sea water desalination industry, there should avoid blind construction and redundant construction. Government should have unified deployment and unified management. And the sea water desalination industries which conform to the national investment oriented enterprise can consider enjoying national, provincial, municipal relevant preferential policies to foreign investment enterprises. Or referencing to the high-tech enterprises, high-tech achievements transformation projects and high-tech products, the industries engaged in sea water desalination can enjoy the support policy in investment, land and tax preferential.

\section{Acknowledgements}

This work was financially supported by the College of Engineer Corps.

\section{References}

[1] Yi Zhang. Assessment of Sustainable Utilization of Water Resources in Hechi City Based on Ecological Footprint Model[J]. The South to North Water Transfer and Water Conservancy Project, 2013, 11(4): 13-15.

[2] Cuimei $\mathrm{Lu}$. Progress and prospect on theory research of water resource value[J]. Resources and Environment the Yangtze Basin, 2009, 18(6): 64-64. 